\title{
Controlled Formation of All-Aqueous Janus Droplets by Liquid-Liquid Phase Separation of an Aqueous Three-Phase System
}

\author{
Qingchun Song, Youchuang Chao, Yage Zhang, and Ho Cheung Shum* \\ Department of Mechanical Engineering, Faculty of Engineering, The University of Hong Kong, \\ Hong Kong (SAR), China \\ * To whom correspondence should be addressed: \\ Email: \\ ashum@hku.hk
}

The supporting information contains the following components:

1) A typical movie showing the evolution of an initial single-phase droplet into a Janus droplet after phase separation. The scale bar is $300 \mu \mathrm{m}$. (Movie S1)

2) The table containing the osmolality of aqueous drop phases with different solute concentrations. (Table S1)

3) The figure illustrating the diameter of the jets under different outer fluid flow rates in glass-capillary microfluidic devices. (Figure S1)

4) A typical movie showing the droplet generation with perturbation in glass-capillary microfluidics and the obtained Janus droplets. The scale bar is $200 \mu \mathrm{m}$. (Movie S2)

5) The table showing the density of each phase of phase-separated DEX, PEtOx and PEG with three different compositions.

6) The figure illustrating the partitioning behavior of $50 \mathrm{wt} \%$ DOPC-50 wt\% DOPS liposomes in the Janus droplets. 
1) See the uploaded video content.

2) The table illustrating the osmolality of the drop phases with different compositions

Table S1. Osmolality of the aqueous solutions*

\begin{tabular}{cccc}
\hline NO. & $\begin{array}{c}\text { DEX T10 } \\
(\mathrm{wt} \%)\end{array}$ & $\begin{array}{c}\text { PEtOx } \\
(\mathrm{wt} \%)\end{array}$ & $\begin{array}{c}\text { Osmolality } \\
(\mathrm{mOsm} / \mathrm{kg})\end{array}$ \\
\hline 1 & 8 & 2 & $54 \pm 1$ \\
2 & 3 & 6 & $57 \pm 2$ \\
3 & 5 & 5 & $73 \pm 1$ \\
\hline NO. & DEX T500 & PEtOx & Osmolality \\
\hline 1 & $(\mathrm{wt} \%)$ & $(\mathrm{wt} \%)$ & $32 \pm 1$ \\
2 & 3 & 5 & $20 \pm 1$ \\
\hline
\end{tabular}

* Average values and standard errors are obtained from 3 independent measurements.

3) The figure shows the diameter of the jets under different outer fluid flow rates in a glass-capillary microfluidic device at constant inner fluid flow rate $Q_{i n}$ without perturbation.

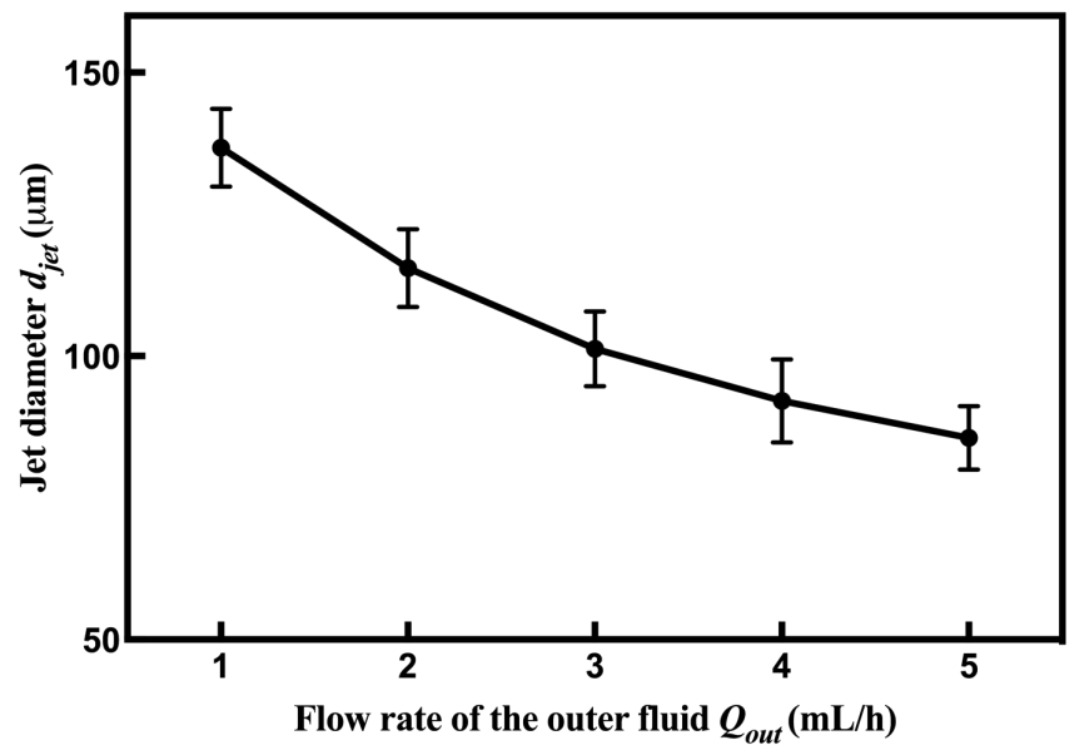

Figure S1. Plot of the diameter of the inner jets $d_{j e t}$ as a function of the outer fluid flow rates $Q_{\text {out }}$, ranging from 1.0 to $5.0 \mathrm{~mL} / \mathrm{h} . Q_{\text {in }}=20 \mu \mathrm{L} / \mathrm{h}$.

4) See the uploaded video content. 
5) The table showing the density of each phase of the phase-separated DEX, PEtOx and PEG with three different compositions.

Table S2. Density of three phases from the phase-separated A3PSs with different compositions*

\begin{tabular}{ccc}
\hline Composition of A3PSs & Phase & $\begin{array}{c}\text { Density } \\
\left(\mathrm{g} / \mathrm{cm}^{3}\right)\end{array}$ \\
\hline $10 \mathrm{wt} \%$ DEX-10 wt\% PEtOx-2 wt $\%$ PEG & PEG-rich phase & 1.039 \\
& PEtOx-rich phase & 1.040 \\
& DEX-rich phase & 1.090 \\
\hline $10 \mathrm{wt} \%$ DEX-15 wt $\%$ PEtOx-2 wt $\%$ PEG & PEG-rich phase & 1.041 \\
& PEtOx-rich phase & 1.047 \\
\hline $\mathrm{wt} \%$ DEX-12 wt $\%$ PEtOx-3 wt $\%$ PEG & DEX-rich phase & 1.110 \\
\hline & PEG-rich phase & 1.037 \\
\hline
\end{tabular}

* Average values are obtained from 3 independent measurements.

6) The figure illustrating the partitioning behavior of $50 \mathrm{wt} \%$ DOPC-50 wt $\%$ DOPS liposomes in the Janus droplets

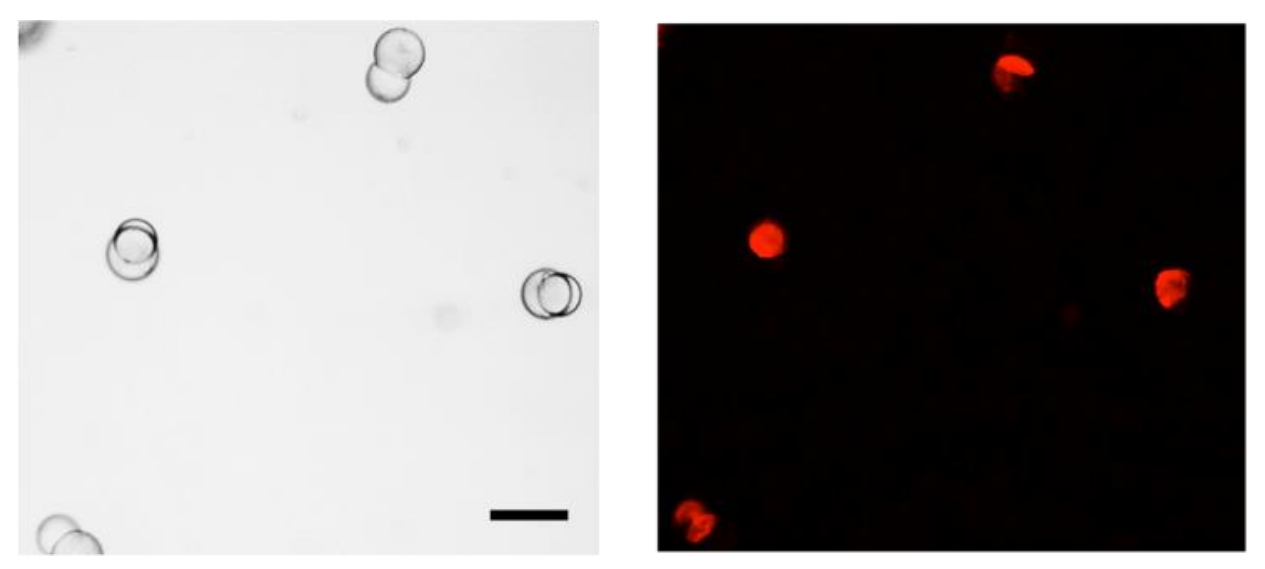

Figure S2. The microscope and fluorescence microscope images showing the partitioning of $50 \mathrm{wt} \%$ DOPC-50 wt $\%$ DOPS Rhodamine-labelled (red) liposomes in the Janus droplets. The $50 \mathrm{wt} \%$ DOPC-50 wt $\%$ DOPS liposomes mainly partition into the DEX-rich phase of the Janus droplets. The scale bar is $200 \mu \mathrm{m}$. 